\title{
ARTHUR OWINO
}

\section{Supervised community treatment and section 17 of the Mental Health Act 1983}

On 17 November 2006 the government announced its plan to introduce a Bill to make a range of amendments to the Mental Health Act 1983. One of the proposals is to introduce supervised treatment in the community to 'ensure that patients comply with treatment and enable action to be taken to prevent relapse' (Department of Health, 2006).

Two conditions need to be fulfilled to facilitate continuous treatment in the community. First, there has to be a mechanism to ensure that a patient participates in their treatment (including taking prescribed medication) while they remain in the community. Second, there must be a way to ensure continuity of this without interfering with the patients' status in the community.

Over the past 20 years, the courts in England and Wales have evolved case law governing the treatment of people with mental disorders in the community based on interpretation of the Mental Health Act 1983. What has emerged is that section 17 of the 1983 Act provides sufficient provisions for the supervised treatment of patients while they remain largely in the community.

\section{Section 17 leave of absence}

Section 17 of the Mental Health Act 1983 allows the responsible medical officer ( $\mathrm{RMO}$ ) to give a detained patient leave of absence from hospital, subject to conditions the RMO deems necessary. These can include a requirement to take medication while on leave and to reside at a particular address, among others. Although the $\mathrm{RMO}$ can require a patient to take medication while on section 17 leave, treatment cannot be forced on the patient while they are in the community. There is no limit to the duration of section 17 leave provided the original authority to detain remains in force.

\section{Compulsory treatment in the community}

\section{$\mathrm{R}$ (on the application of CS) v. Mental} Health ReviewTribunal and Another [2004]

C.S. was first admitted to hospital in 1991 with a psychotic episode. In January and February 1993, she was readmitted with further psychotic episodes. There was, however, no further contact with psychiatric services until 1998, when she gave a history of having an average of five psychotic episodes per year, characterised by bizarre auditory and visual hallucinations. She had several admissions to hospital (formally and informally), was successfully treated, and upon discharge from hospital invariably discontinued her medication, with subsequent deterioration of her mental health necessitating readmission to hospital.

In May 2003, she was readmitted to hospital under section 3 and had a slow response to treatment with oral antipsychotic medication. After review in October 2003 her medication was changed to depot pipotiazine palmitate and her detention was also renewed.

She made good progress and was granted leave with good results. By January 2004 the frequency of attendance at hospital for a ward round was once every 4 weeks. She saw a psychologist once a week, assertive outreach workers twice a week and received her depot injection on the ward every 4 weeks.

She had a mental health review tribunal hearing in February 2004 during which the RMO recommended that in view of her history of non-adherence, disengagement with services and lack of insight to manage her illness as a voluntary patient, detention under section 3 should continue in order for the treatment to be continued.

The mental health review tribunal decided to continue her detention under section 3. C.S. then sought to quash the decision as unlawful and irrational, characterising it as merely a method of enforcing cooperation with the assertive outreach team.

Considering how the approach to C.S.'s treatment could work within the framework of the Mental Health Act 1983, the judge Pitchford, J. stated:

\footnotetext{
'Viewed as a whole the course of treatment should be seen ... as a continuing responsive programme, during which the need for treatment in hospital and on leave was being constantly reassessed depending upon circumstances including C.S.'s response to asser tive outreach service and the ward round. Until such a time as the transition was complete, the element of treatment at hospital remained a significant part of the whole'.
}

He then ruled that 'treatment in a hospital under section 3 can take place daily without overnight stays in hospital'. 
可

editorial
Therefore, treatment under section 3 can lawfully continue without a patient spending any nights in a hospital bed. All that is required is for a significant part of the treatment, taken as a whole, to take place in a hospital. In the case of C.S. the significant part of the treatment was attendance at ward round every 4 weeks.

\section{Renewal of detention while in the community}

\section{B v. Barking Havering and Brentwood Community Healthcare NHS Trust [1991]}

The appellant had a history of repeated admissions to hospital with amphetamine-induced psychosis. In November 1997 her RMO applied for the authority to renew her detention under section 3, although by that time her leave was extended to 7 days a week, to be reviewed weekly.

She made an application to the Court of Appeal on the basis that she did not fulfil the renewal criteria set out in section 20 since she was spending most of her time away from hospital, returning only for assessment, and that that assessment did not constitute treatment, and that in those circumstances she was not detained for the purpose of the section.

The Court of Appeal held that as long as a patient's medical treatment, viewed as a whole, involved treatment in a hospital, the requirement of section 20 could be met. The fact that a patient happened to be away from hospital at the time of the renewal of authority for detention did not mean that they were no longer 'detained' for treatment. Such a renewal would be lawful even if the periods of hospital care could be classified as being for the purpose of assessment, rather than the actual treatment.

This judgment was seen as re-introducing the 'long leash' that doctors had been asked to abandon since $\mathrm{R} v$. Hallstrom and Another, ex parte W; R v. Gardner and Another ex parte L [1986], where the court ruled that renewal of authority to detain a patient under section 20 can only be used when the doctor believes that the mental disorder of the patient necessitates a further period of detention for treatment as an in-patient.

\section{$R$ (on the application of DR) $v$. Mersey Care NHS Trust [2002]}

The claimant D.R. had schizophrenia, and her first admission to hospital was around 1991. Prior to her admission in September 2001 (which led to her bringing proceedings for judicial review) she had been admitted to the same unit on five occasions. The pattern of her contacts with psychiatric services was that of compulsory admission and successful treatment with medication; following which upon discharge she invariably refused to accept medication based on her belief that she was not ill. Nonadherence to treatment then led to deterioration in her mental state and subsequent compulsory readmission.
D.R.'s admission in September 2001 was precipitated by her refusal to take medication in the community leading to a relapse. Following admission and resumption of treatment, D.R.'s condition improved. However, she refused to engage with hospital staff, and the team treating her concluded that if the revolving door pattern of care was to be halted, a mechanism had to be found which enabled staff to engage with her and help her to develop an insight into her condition, which ultimately would lead her to take her medication voluntarily.

A plan was developed, granting her leave under section 17 with conditions that she attend hospital between 09:00 and 17:00 h 3 days each week and accept the administration of medication by injection at her home.

In December 2001, D.R.'s application for discharge was heard by the mental health review tribunal which, being aware of the extensive section 17 leave granted to her, declined to direct discharge.

In February 2002, D.R.'s RMO applied for renewal of the powers of detention under section 20(3) and the hospital managers agreed that a longer period of detention was necessary.

D.R. brought proceedings for judicial review, challenging the decision to renew authority for her detention beyond March 2002, stating that renewal was appropriate only where the plan for the patient's treatment was as an in-patient. She argued that in her case the treatment was only as an out-patient.

In his judgment, Wilson, J. stated:

'Any distinction between treatment at a hospital and in a hospital was too subtle. It would be an impermissible and illogical gloss on the Act to make lawfulness depend upon a plan to put the patient at times into a hospital bed'

Wilson, J. elaborated by stating that 'when I eat at a restaurant, I eat in a restaurant' and further added that 'there is no magic in a bed'. The judge also drew attention to the interpretation of 'medical treatment' in section 145:

'medical treatment includes nursing and also includes care, habilitation and rehabilitation under medical supervision

and paragraph 20(1) of the Mental Health Act Code of Practice:

'Leave of absence can be an important part of a patient's treatment plan'.

Wilson, J. therefore held that a significant component of the plan for D.R. was treatment in hospital and that the conditions for renewal of authority for detention as set out by section 20(4) were satisfied.

\section{Discussion}

There has been extensive debate within British and international psychiatry about compulsory treatment in the community. Proponents argue that such treatment reduces hospital readmission, improves adherence to medication and permits better use of community resources (Mclvor, 2001). Critics, however, argue that such treatments infringe civil liberties, extend unwanted 
coercion into the community and may actually drive people away from treatment (Mulvey et al, 1987; Miller, 1999). Sensky et al (1991) found that a psychiatrist's decision to recommend a patient for treatment with a community treatment order (if such a provision existed) will depend predominantly on specific criteria related to the patient's recent past, particularly in terms of default from follow-up. It has been argued that since services have already moved into the community to a great extent it seems difficult now to continue to argue that compulsory treatment should only occur in hospital (Eastman, 2006).

The Mental Health Act 1983 does not distinguish between treatment in hospital or in the community under continuing detention. Case law in England and Wales has evolved to allow the detention and renewal of detention of patients who remain in the community. Section 17 allows for the treatment of patients who remain largely in the community so long as a 'significant' element of treatment takes place in hospital, irrespective of the amount of time they spend away from hospital. The 'significant' element of treatment in hospital can be regular attendance at ward round for review of the mental state and the leave status; regular screening for use of illicit drugs; administration of prescribed medication; attendance at therapeutic groups; etc.

However, patients who refuse to take their medication while in the community cannot be compelled to do so under section 17 . The treatment can only be enforced once the patient is recalled to hospital where provisions in part IV of the Act, if relevant, can be enforced. (Similar provisions are contained in the community treatment orders proposed in the Amendment Bill.) This is a sensible and pragmatic condition of the section 17 leave, since enforcing treatment while a patient is in the community can pose significant risks both to the patient and the treating professionals. On one hand attempts to force a patient to take a treatment they do not want has the potential to cause harm to the professionals enforcing the treatment and the patient (imagine wrestling with a patient in their kitchen to administer a depot injection!). On the other hand, professionals are unlikely to be equipped to deal adequately with any adverse reactions a patient may suffer from the administered medication. Such risks are best managed if treatment is enforced under hospital conditions. Thus any future legislation authorising the compulsory treatment of patients in the community could be difficult to enforce.

The renewal of authority for detention can be completed while a patient is in the community, so long as the patient remains 'liable to be detained' under the Mental Health Act 1983. A patient remains liable to be detained so long as a significant part of their treatment takes place in hospital. In these circumstances, the authority for detention can be renewed without having to bring them back to hospital for the process to be completed.

The legal framework for the supervised treatment of patients while they remain largely in the community already exists within the provisions of section 17. Common sense dictates that patients are not forced to accept treatment while they are in the community (owing to potential risks of coercion), but should be admitted to hospital. Furthermore, the current state of mental health law does not permit medication to be enforced outside hospital, although many patients may already feel they are coerced into taking their medication. It is also well established that in order to properly facilitate the care of patients while they remain largely in the community adequate resources are required for regular support and monitoring of their care. Therefore, improvement of the overstretched community psychiatric services is needed to ensure the success of care in the community, and not more legislation. We already have the provisions of section 17

Attempts to use legislation to patch-up deficiencies in service provision are likely to lead to undesired consequences. Restriction of liberty without the reciprocal provision of adequate care and support could result in eroding patients' self-determination and dignity and might deter them from future contact with psychiatric services. Compulsory treatment in the community will only work when the principle of reciprocity, the right to adequately resourced care in exchange for further infringement of civil liberties, is applied (Eastman, 1994). The emphasis should be given to service provision, such as the mental health team's ability and willingness to deliver required care (Geller, 1990).

\section{Declaration of interest}

None.

\section{References}

DEPARTMENT OF HEALTH (2006). Mental Health Bill. What Changes

to the Act are to be Made?

http://www.dh.gov.uk/en/

Policyandquidance/

Healthandsocialcaretopics

Mentalhealth/DH_4131958

EASTMAN, N. (1994) Mental Health Law: civil liberties and the principle of reciprocity. BMJ, 308, 43-45.

EASTMAN, N. (2006) Reformingmental health law in England and Wales. BMJ, $332,737-738$

GELLER, J. L. (1990) Clinical guidelines for the use of involuntary out-patient treatment. Hospital and Community Psychiatry, 41,749-755.

McIVOR, R. (2001) Care and compulsion in community psychiatric treatment. Psychiatric Bulletin, 25, 369-370.

MILLER, R. D. (1999) Coerced treatment in the community. Psychiatric Clinics of North America, 22, 183-196.

MULVEY, E. P., GELLER, J. L. \& ROTH, L. H. (1987) The promise and peril of involuntary outpatient commitment. American Psychologist, 42, 571-584.

SENSKY, T., HUGHES, T. \& HIRSCH, S. (1991) Compulsory psychiatric treatment in the community. II. A controlled study of patients whom psychiatrists would recommend for compulsory treatment in the community. British Journal of Psychiatry, 158, 799-804.

B v. Barking Havering and Brentwood Community Healthcare NHS Trust [1991] 1 FLR 106.

R v. Hallstrom and Another, ex parteW; R v. Gardner and Another ex parte L [1986] 2 AllER 306

$R$ (on the application of CS) v. Mental Health ReviewTribunal and Another [2004] EWHC 2958 (Admin).

R (on the application of DR) v. Mersey Care NHS Trust [2002] EWHC 1810 (Admin).

Arthur Owino Specialist Registrar in Forensic Psychiatry, Shaftesbury Clinic Springfield University Hospital, 61 Glenburnie Road, London SW17 7DJ, email: arthurowino@doctors.org.uk

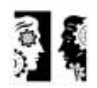

editorial 